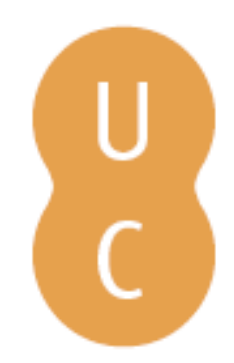

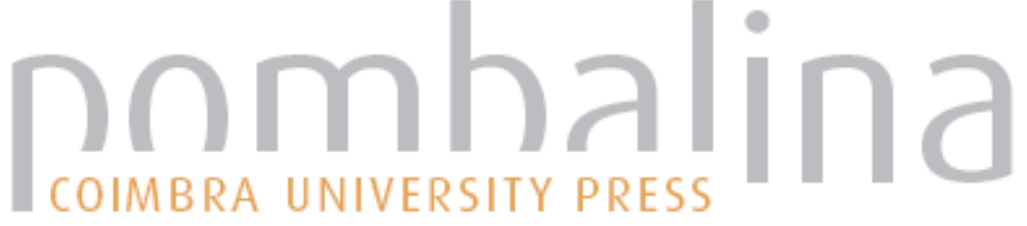

\section{A historiografia régia portuguesa anterior ao Conde de Barcelos}

Autor(es): $\quad$ Moreira, Filipe Alves

Publicado por: Imprensa da Universidade de Coimbra

URL

persistente: URI:http://hdl.handle.net/10316.2/31557

DOI: $\quad$ DOI:http://dx.doi.org/10.14195/978-989-26-0405-3_3

Accessed : $\quad$ 26-Apr-2023 09:59:09

A navegação consulta e descarregamento dos títulos inseridos nas Bibliotecas Digitais UC Digitalis, UC Pombalina e UC Impactum, pressupõem a aceitação plena e sem reservas dos Termos e Condições de Uso destas Bibliotecas Digitais, disponíveis em https://digitalis.uc.pt/pt-pt/termos.

Conforme exposto nos referidos Termos e Condições de Uso, o descarregamento de títulos de acesso restrito requer uma licença válida de autorização devendo o utilizador aceder ao(s) documento(s) a partir de um endereço de IP da instituição detentora da supramencionada licença.

Ao utilizador é apenas permitido o descarregamento para uso pessoal, pelo que o emprego do(s) título(s) descarregado(s) para outro fim, designadamente comercial, carece de autorização do respetivo autor ou editor da obra.

Na medida em que todas as obras da UC Digitalis se encontram protegidas pelo Código do Direito de Autor e Direitos Conexos e demais legislação aplicável, toda a cópia, parcial ou total, deste documento, nos casos em que é legalmente admitida, deverá conter ou fazer-se acompanhar por este aviso. 
Maria do Rosário Ferreira

Coordenaçáo

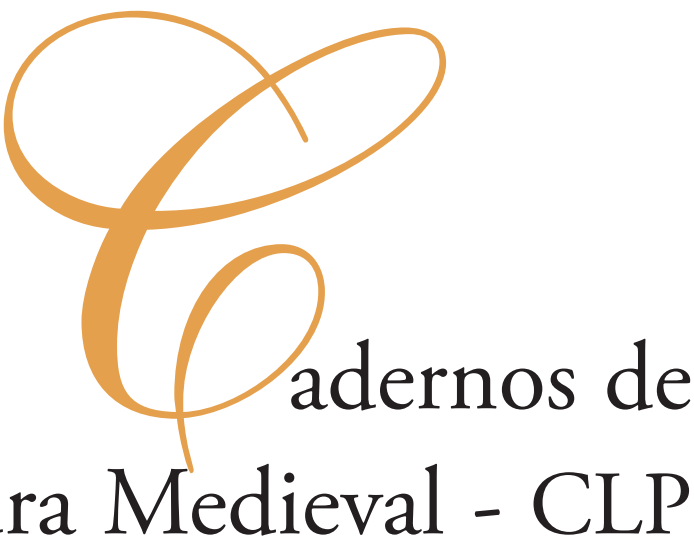

O Contexto Hispânico da Historiografia Portuguesa nos Séculos XIII e XIV

Em mémoria de Diego Catalán 
Filipe Alves Moreira

Estudante de doutoramento da FLUP; bolseiro da FCT; investigador do Seminário Medieval de Literatura, Pensamento e Sociedade (IF-FLUP/FCT).

\title{
A HISTORIOGRAFIA RÉGIA PORTUGUESA ANTERIOR AO CONDE DE BARCELOS
}

\author{
«E os que hoje movendo impossibilidades, \& fazendo \\ argumentos, \& conjecturas querem encontrar os antigos, \\ andão ás cegas adiuinhando, porque [...] hoje faltão muitos \\ dos papeis que os antigos tiverão» \\ Pedro de Mariz, prólogo da Crónica de D. Afonso IV de Rui de Pina
}

Tentarei fazer o ponto da situação sobre a historiografia régia nacional anterior às obras do Conde de Barcelos, entendendo-se por tal a historiografia em língua portuguesa centrada nas figuras dos reis e com possíveis ligaçôes à corte. O percurso será simples e pretende-se claro: revisitarei os estudos mais importantes até agora realizados neste âmbito, introduzirei algumas novas propostas entretanto avançadas, darei conta das zonas de maior incerteza e fragilidade em tudo isto e, concomitantemente, elencarei um conjunto de pontos ainda e sempre em aberto.

\section{A historiografia régia portuguesa anterior ao Conde de Barcelos e a crítica}

Segundo nos ensinou um inolvidável mestre, o direito Romano começou por não existir. E o mesmo terá sucedido com a historiografia régia portuguesa da Idade Média, não apenas como entidade em si, mas também enquanto objecto de estudo da crítica. É sabido, por exemplo, que, no tempo de A. Herculano, considerava-se praticamente inexistente toda e qualquer historiografia em língua portuguesa (não incluindo na conta os Livros de Linhagens) anterior a Fernão Lopes. Intuía-se já que algo teria existido, sem dúvida, até 
porque alguma coisa seriam aquelas estórias que D. Duarte mandava fossem convertidas em Crónicas. Mas tudo isso pouco mais teria sido, pensava-se, do que vagas e inconexas tentativas acerca das quais, e devido à ausência de testemunhos directos, nada haveria a dizer por parte de uma crítica que se pretendia científica ${ }^{1}$. Com uma ou outra interessante excepçáo a que adiante me referirei, era este o panorama à entrada dos anos 50 do século passado.

O que o mudou foram os decisivos estudos, por essa época realizados, do então muito jovem Lindley Cintra. Cintra era - e assim se terá mantido durante toda a vida - um fiel discípulo da escola filológica de R. Menéndez Pidal, o que, e do ponto de vista que aqui mais nos interessa, significa basicamente que o seu trabalho assentava em dois grandes princípios: por um lado, em certa secundarização da reflexáo teórica, em prol de uma leitura «em estado natural» dos textos ${ }^{2}$; por outro, no estabelecimento de relaçôes entre manuscritos e/ou entre textos enquanto procedimento metodológico de base, sobre o qual viriam a assentar, e no qual se viriam a inspirar, posteriores consideraçóes de ordem literária, histórica ou cultural.

Munido destes princípios, e favorecido por «dotes críticas excepcionales ${ }^{3}$ », Cintra entendeu a emergência da cronística régia portuguesa da seguinte e resumida maneira ${ }^{4}$ : D. Dinis, rei que teria adoptado o português como língua oficial e cujo investimento em diversas áreas culturais parece razoavelmente atestado, terá congregado em torno de si uma corte que constituiria o ambiente em que pela primeira vez se reuniriam entre nós as condições necessárias à elaboração de uma memória do reino em língua vulgar. A ausência de uma tradição prévia obrigaria, porém, a que esse impulso inaugural de constituição de uma historiografia portuguesa se apoiasse, num primeiro momento, em traduçôes. Daí a tradução, explicitamente atribuída à iniciativa deste rei, da Crónica do Mouro Rasis do árabe para o português, e daí, provavelmente também, a tradução, desta vez do castelhano para o português, de certa versão da Estoria de España conservada num manuscrito da primeira metade do século $\mathrm{XIV}^{5}$. O momento decisivo de passagem das traduçóes às

\footnotetext{
${ }^{1}$ Repare-se, a título exemplificativo, que, ao publicar a chamada Crónica Breve do Arquivo Nacional (texto redigido em 1429) nos Portugaliae, Herculano declarava-a explicitamente a crónica em vulgar mais antiga que possuíamos.

${ }^{2}$ Veja-se, a propósito, o verbete a ele dedicado em Lanciani e Tavani (2000); e também a muito interessante entrevista/conversa de José Mattoso e Lindley Cintra recolhida em Faria (1999).

3 Segundo diz Menéndez Pidal em carta a Américo Castro de Janeiro de 1955, na qual reconhece a necessidade de rever boa parte das suas teses sobre as crónicas medievais à luz dos trabalhos de Cintra: Villanueva (1991: 454).

${ }^{4}$ Sumario as conclusóes a que este autor chega no volume introdutório da sua edição da Crónica Geral de Espanha de 1344, particularmente no último capítulo, dedicado às origens e evolução da historiografia medieval portuguesa até à Crónica de 1419: Cintra (2009).

${ }^{5} \mathrm{O}$ conhecido 8817 da BNE, normalmente referenciado pela designação de ms. $A$ que lhe deu Menéndez Pidal ao estudar a tradição manuscrita da Estoria de España.
} 
produçóes originais apenas seria alcançado, todavia, por um filho e de certa forma continuador das ideias deste rei: D. Pedro Afonso, terceiro conde de Barcelos. Teria sido ele quem, graças ao ambiente proporcionado pela corte de seu pai e a contactos desde cedo estabelecidos com a coroa castelhana, reuniria boa soma de materiais historiográficos para posteriormente se abalançar à feitura de obras próprias. Nesse sentido, e concentro-me agora especificamente nos textos dedicados à história dos reis de Portugal, D. Pedro teria começado por traduzir, ampliar levemente e actualizar o que a este respeito dizia certa Crónica de Veinte Reyes castelhana, originando assim o texto da chamada IVa Crónica Breve e, pouco depois, teria aproveitado este seu trabalho incluindo-o, com numerosos acrescentos, primeiro no Livro de Linhagens e seguidamente na Crónica de $1344^{6}$, cuja autoria lhe era então, e pela primeira vez, atribuída ${ }^{7}$. Por isso, e em suma, para Lindley Cintra «é $[. .$.$] na corte dos reis de Portugal (ou em ambientes a ela intimamente ligados)$ que está o ponto de partida da historiografia em língua portuguesa, como é na corte dos reis de Castela que está o da historiografia em língua castelhana ${ }^{8}$ ».

Uma das peças mais importantes desta construção era a IVa Crónica Breve, que, como se viu, Cintra considerava a mais antiga crónica portuguesa conhecida. Esta $I V^{a}$ Crónica Breve, texto historiográfico incluído num manuscrito da segunda metade do século XV oriundo do Mosteiro de Santa Cruz de Coimbra e actualmente à guarda da Biblioteca Pública do Porto 9 , não era, de todo, desconhecida: salva por Herculano da voragem que acompanhou as guerras liberais e a desamortização dos conventos, foi por ele mesmo publicada nos Portugaliae Monumenta Historica em 1856, e o facto de ela albergar uma curiosa narrativa centrada em D. Afonso Henriques tornara-a já objecto de alguma atenção ${ }^{10}$. Simplesmente, a datação tardia do suporte material desta pequena crónica, aliada a um insuficiente conhecimento, por parte dos estudiosos portugueses, da produção histo-

${ }^{6}$ Conhecem-se apenas, para esta secção, testemunhos da segunda redacção da Crónica de 1344; todavia, tanto a análise interna do seu texto (veja-se o reinado de D. Dinis, afinal um dos grandes argumentos para atribuir a sua feitura ao Conde de Barcelos), como a comparação com outros textos que com ela se relacionam (IVa Crónica Breve e Crónica de 1419) permitem garantir que a segunda redacçáo manteve, neste ponto, as linhas gerais da primeira. Daí que, por razôes de clareza expositiva, fale sempre e só em Crónica de 1344, da mesma maneira que é usual falar-se em Livro de Linhagens do Conde D. Pedro não obstante as reformas (cuja extensão está sujeita a debate) que o seu texto foi conhecendo.

7 Embora a origem portuguesa deste texto tivesse já sido defendida por José de Bragança, conforme Cintra náo se esquece de advertir: Cintra (2009: XLV-XLVI).

${ }^{8}$ Cintra (2009: CDXIV).

${ }^{9}$ Ms. 86 do Fundo de Santa Cruz de Coimbra da BPMP.

${ }^{10}$ A começar pelo próprio Herculano, que, embora mencione como fonte de inspiração as Crónicas de Acenheiro, nela se terá também baseado para a redacção do célebre «Bispo Negro", texto pertencente às Lendas e Narrativas. 
riográfica castelhana que com ela mantém inegáveis relaçôes, tinha vindo a obstaculizar a sua correcta perspectivação ${ }^{11}$. Tanto quanto sei, apenas o Tenente-Coronel Costa Veiga a tinha já considerado como um texto mais antigo do que se supunha, chegando, inclusivamente, a datá-la de meados do século XIV, pelo menos ${ }^{12}$. Mas Costa Veiga desconhecia a castelhana e então inédita Crónica de Veinte Reyes, peça não menos importante em todo este processo. E a vantagem dos trabalhos de Cintra estava precisamente nisto: em ter contado com um panorama mais amplo, no seio do qual os textos portugueses eram constantemente postos em diálogo com os castelhanos, também eles alvo de particulares atençôes. Lição fundamental, esta, apesar de nem sempre posta em prática pela crítica portuguesa ${ }^{13}$.

Dos trabalhos de Cintra, e com pressupostos metodológicos muito próximos ${ }^{14}$, partiu Diego Catalán ${ }^{15}$, em publicaçóes de finais dos anos 50 posteriormente revistas e reunidas num livro, hoje clássico, a que chamou De Alfonso X al Conde de Barcelos ${ }^{16}$. Catalán aceitou sem reservas a colocaçáo dos textos portugueses proposta por Cintra, confirmando a prioridade da IVa Crónica Breve face ao Livro de Linhagens e à Crónica de 1344, mas um estudo cerrado da primeira destas obras levou-o a afastar-se de outras teses do seu predecessor mediante uma operação de adição e duas importantes operaçóes de subtracção.

Em primeiro lugar, recorreu ao testemunho de um obscuro historiógrafo eborense do século XVI, Cristóvão Rodrigues Acenheiro, para caracterizar a crónica de que a chamada IVa Crónica Breve seria um fragmento ${ }^{17}$, concluindo que essa obra teria sido redigida entre

${ }^{11}$ Ainda em 1948, A. Pimenta declarava impossível determinar se o texto da IVa Crónica Breve era anterior ou posterior à Crónica de D. Afonso Henriques de Duarte Galvão (1505): ed. Pimenta (1948: 75).

12 Veiga (1939: 225-228). Também Magalhães Basto chegou a estar próximo destas conclusões, julgando ver na IVa Crónica Breve um testemunho de uma redacção da Crónica de 1344 mais antiga do que as actualmente conhecidas: Basto (1960: 192).

${ }_{13}$ Basta dar como exemplo o caso de A. J. Saraiva, que, embora mencione frequentes vezes a Crónica de Veinte Reyes nos seus estudos sobre a IVa Crónica Breve e as tradiçōes lendárias de D. Afonso Henriques (o que nem sempre sucede com outros autores), manifesta a cada passo uma clara incompreensấo do seu significado e do lugar por ela ocupado na evoluçáo da historiografia ibérica. Posso documentar esta ideia com as suas afirmações acerca do chamado «episódio de Badajoz» num, aliás interessante, artigo da década de 60 em que só o desconhecimento dos processos de construção da crónica castelhana e suas relaçóes com a obra do Arcebispo de Toledo - náo com a de Lucas de Tuy, como, decerto por equívoco, diz Saraiva - podem explicar as suas afirmaçōes: Saraiva (1969).

${ }^{14}$ Pode ver-se uma notável síntese do labor de Catalán no texto de Inés Fernández-Ordóñez presente neste volume. O próprio Catalán vai enxameando os seus livros com anotaçôes memorialísticas e reflexôes/revisôes metodológicas do seu trabalho. São, quanto a isso, particularmente apelativas as palavras por ele deixadas em Catalán (1976: 7-251).

${ }^{15}$ A dívida de Catalán para com os trabalhos de Cintra não deixou nunca de ser reconhecida: Catalán (1992: 7).

${ }^{16}$ Catalán (1962).

${ }^{17} \mathrm{O}$ carácter fragmentário da $I V^{a}$ Crónica Breve, que parece garantido pela sua epígrafe ("Aqui se compeça a estorea dos reis de purtugall») foi um aspecto rapidamente notado e destacado por Catalán (1962: 224). 
1341-1342 e seria basicamente uma algo rudimentar História da Península Ibérica desde os tempos de Pelayo até à batalha do Salado, quadrando-lhe por isso o nome de Crónica Portuguesa de Espanha e Portugal. Foi possível chegar a esta conclusão porque Acenheiro, de acordo com algumas características típicas da historiografia nacionalista do século XVI, contestou vivamente a bastardia de D. Teresa alegando em seu favor duas «corónicas velhisimas ${ }^{18}$ ", uma das quais, cujo conteúdo abarcava aquele lapso temporal, denotava evidentes pontos de contacto com o texto da IVa Crónica Breve ${ }^{19}$. Esta poderia, assim, considerar-se um excerto daquela.

Em segundo lugar, e divergindo das ideias de Cintra a respeito da IVa Crónica Breve, Catalán subtraiu essa Crónica Portuguesa de Espanha e Portugal quer à iniciativa do Conde de Barcelos, que assim se teria limitado a usá-la como uma das suas fontes, quer à influência da cronística régia de inspiração afonsina.

Considero este último aspecto o ponto crucial das suas teses e a pedra angular em que deve assentar qualquer tentativa de explicação do surgimento de uma cronística nacional. Por isso, e também porque a crítica portuguesa nem sempre parece ter compreendido particularmente bem o que está em causa, permito-me demorar um pouco mais nesta questão, prometendo desde já simplificar o melhor que puder a natural complexidade destes assuntos.

Admitida a evidente proximidade da Crónica de Veinte Reyes e da Crónica Portuguesa de Espanha e Portugal pelo menos no que ao reinado de D. Afonso Henriques diz respeito, Catalán concentrou aí a sua atenção chegando a conclusôes bem diferentes das que propusera Cintra. Com efeito, segundo o grande investigador espanhol demonstrou de forma definitiva, o texto da IVa Crónica Breve (e portanto a Crónica Portuguesa de Espanha e Portugal) não pode ser considerado uma tradução ampliada e actualizada da História de Portugal presente na Crónica de Veinte Reyes. A hipótese contrária, ou seja, que a Crónica de Veinte Reyes tenha usado a Crónica Portuguesa de Espanha e Portugal também não é, por sua vez, sustentável, bastando atentarmos na cronologia então estabelecida para a obra castelhana (fins do século XIII ou princípios do seguinte ${ }^{20}$ ) para verificarmos que tal cenário nunca poderia sequer ter sido equacionado por Diego Catalán, e isto apesar

\footnotetext{
${ }^{18}$ Acenheiro (1824: 5).

19 Para além dos casamentos e descendência de Afonso VI (incluindo o animado episódio do baptismo da Moura Zaida), Acenheiro mencionou ainda alguns aspectos do reinado de D. Afonso Henriques retirados da mesma crónica velha e coincidentes com o que se lê na IVa Crónica Breve.

${ }^{20}$ E também esta cronologia tinha sido uma importante aportação de Cintra, pois Menéndez Pidal julgava a Crónica de Veinte Reyes posterior à de 1344.
} 
de uma parte da crítica portuguesa ter vindo a atribuir-lhe tão equivocada opinião ${ }^{21}$. $\mathrm{Na}$ verdade, afastada a dependência da crónica portuguesa em relação à castelhana, a conclusão a que o mestre chegava só podia ser uma: pelo menos no que ao reinado de D. Afonso Henriques diz respeito, a Crónica de Veinte Reyes e a Crónica Portuguesa de Espanha e Portugal usam uma fonte comum; essa fonte, precisa ainda Catalán, seria com toda a probabilidade um texto historiográfico português ${ }^{22}$ no qual, e tal como naquelas duas obras se verifica, a história do nosso primeiro rei era constituída por uma mistura de trechos narrativos, analísticos e genealógicos. Entretanto, analisando o pouco que hoje podemos conhecer da parte da Crónica Portuguesa de Espanha e Portugal dedicada aos reis asturianos, leoneses e castelhanos de Pelayo a Afonso VI (e já vimos que é graças a Acenheiro que temos acesso a estes aspectos), continua a verificar-se a independência da crónica portuguesa em relação à historiografia afonsina, pois a sua fonte foi aqui uma versão interpolada do Liber Regum ${ }^{23}$ que ostenta a curiosa particularidade de ter sido aparentemente a mesma que os redactores da Estoria de España usaram ${ }^{24}$.

As consequências deste novo enquadramento textual para a questão das origens da historiografia régia portuguesa parecem-me evidentes e podem enunciar-se em três alíneas:

(i): a cronologia do seu nascimento não pode mais ser simplistica e apressadamente colocada em meados do século XIV, pois há sinais inequívocos da elaboração de pelo menos um texto de características historiográficas em data anterior a finais do século XIII;

(ii): o surgimento de uma cronística régia em língua portuguesa é independente da iniciativa historiográfica de Afonso X e seus seguidores castelhanos;

(iii): não obstante esta independência, a primitiva historiografia em língua portuguesa e a primitiva historiografia em língua castelhana usaram alguns

${ }^{21}$ Sucede, com efeito, que a crítica portuguesa tendeu muitas vezes a simplificar as teses de Catalán, vendo nas suas palavras, erroneamente, a ideia de que a Crónica Portuguesa de Espanha e Portugal tinha sido o antecedente, não só da IVa Crónica Breve, mas também da Crónica de Veinte Reyes. Documente-se com Maurício (1989), que considero o melhor estudo até hoje feito acerca da formação e evolução da lenda de Ourique. Não obstante, há que reconhecer que o próprio Catalán, nisso seguido por mim em Moreira (2008), contribuiu para o equívoco, falando quase sempre e só em «IVa Crónica Breve»».

${ }^{22}$ É de toda a justiça sublinhar que, denotando embora hesitações várias, a existência de um texto historiográfico português que pudesse ter sido fonte da Crónica de Veinte Reyes para o reinado de D. Afonso Henriques tinha já sido assinalada por Babbitt (1934: 211). E pode ainda notar-se, de passagem, que Babbitt, ao contrário do que viria a ser habitual em alguns estudos portugueses, defendia a unidade da estória lendária de D. Afonso Henriques, aspecto a que adiante me referirei.

23 Sendo que, e como pertinentemente notou Catalán, também na parte dedicada aos reis portugueses a estrutura da Crónica Portuguesa de Espanha e Portugal é essencialmente a mesma do Liber Regum, ou seja, um esquema genealógico de base em que se vão inserindo narrativas de extensão variável.

${ }^{24}$ Para tudo isto, veja-se Catalán (1962: 205-288). 
materiais comuns, denotando assim certo intercâmbio textual entre os dois reinos pelo menos desde a segunda metade de duzentos.

Consequentemente, o quadro traçado por Lindley Cintra perdia uma parte da sua operacionalidade e os primórdios da historiografia régia portuguesa, se por um lado se tornavam mais precisos, por outro recuperavam uma significativa e agora paradoxal obscuridade. De tal forma assim foi, que o próprio Diego Catalán se absteve de traçar as origens da historiografia em língua portuguesa em moldes diversos dos de Lindley Cintra, apesar das conclusôes tão diferentes a que chegara.

\section{A Primeira Crónica Portuguesa: datação, conteúdo e origem}

Foi com base neste novo panorama traçado pelo De Alfonso X al Conde de Barcelos que pretendi, não há muito, situar e caracterizar um pouco melhor os primórdios da cronística régia portuguesa. Mais concretamente, concentrei-me naquele texto historiográfico fonte da Crónica de Veinte Reyes e da Crónica Portuguesa de Espanha e Portugal, que me pareceu ser o mais antigo e palpável vestígio de uma actividade cronística nacional, e procurei responder às seguintes, e aparentemente simples, questóes: qual a data aproximada da sua redacçấo? Qual o seu conteúdo? Quais os seus promotores?

O problema da data aproximada da sua redacção tinha pelo menos um caminho seguro a percorrer: circunscritas as duas obras que recorreram directamente a esse texto primordial, haveria que estabelecer a cronologia de cada uma delas e considerar a datação da mais antiga como sendo o término ad quem da sua fonte. Diego Catalán, ao dar Veinte Reyes como seguramente anterior à crónica portuguesa, situando-a, com Cintra, por volta de 1300, fornecera já o essencial da operação. Mas investigaçóes ulteriores, sobretudo de Inés Fernández-Ordóñez ${ }^{25}$ e Mariano de la Campa ${ }^{26}$, que conseguiram precisar o lugar do texto castelhano na evolução da cronística afonsina, permitiram avançar ainda mais, pois, ao considerarem a Crónica de Veinte Reyes como uma família de manuscritos da Versão Crítica da Estoria de España ${ }^{27}$, a qual terá com toda a probabilidade sido redigida na fase

\footnotetext{
${ }^{25}$ Fernández-Ordóñez (1993).

${ }^{26}$ Campa Gutiérrez (2009).

${ }^{27}$ Família de manuscritos que tem a particularidade de copiar a Versão Crítica a partir do reinado de Fruela II, juntando-lhe, a seguir à morte de Fernando II de Leão, cópias da Crónica de Castela (reinados de Henrique I de Castela e Afonso IX de Leão, bem como parte dos de Afonso VIII de Castela e Fernando III) e
} 
final da vida de Afonso X, entre 1282 e 1284, levaram a que se tivesse de recuar a datação do texto historiográfico português por ela usado até, quando muito, ao princípio dos anos 80 do século XIII. E se este recuo parece à primeira vista pouco relevante, a verdade é que ele tem pelo menos uma séria consequência: graças a ele, pode pela primeira vez encarar-se a possibilidade de ter existido uma actividade historiográfica em Portugal e em português ainda durante a época de D. Afonso III.

Quanto ao conteúdo desse texto, a grande questáo é sabermos se ele abrangeria apenas o reinado de D. Afonso Henriques (pois disso estamos seguros) ou incluiria mais alguma matéria. Nesse sentido, perguntei-me se não haveria, nos restantes reinados portugueses da Crónica Portuguesa de Espanha e Portugal (conhecidos na íntegra, recorde-se, através da IV Crónica Breve) algo que pudesse remontar ao mesmo texto em que o seu redactor tinha seguramente colhido a história do nosso primeiro rei, e, baseado em argumentos de diferente natureza, cheguei à conclusão de que ele incluiria já muito provavelmente o reinado de D. Sancho I e possivelmente também os reinados seguintes, até o de D. Sancho II pelo menos, numa forma não muito diferente daquela que actualmente se pode ler no manuscrito da $I V^{a}$ Crónica Breve ${ }^{28}$. Tratar-se-ia, portanto, não apenas de uma história do reinado de Afonso Henriques, mas de uma verdadeira crónica dos reis de Portugal, talvez a mais antiga alguma vez escrita em vulgar, razão pela qual a poderemos apelidar de Primeira Crónica Portuguesa ${ }^{29}$. Devo confessar que o próprio Diego Catalán não andou longe de um cenário semelhante, pois na introdução à sua edição da Crónica de 1344 refere-se ao texto português que foi fonte da Crónica de Veinte Reyes e da Crónica Portuguesa de Espanha e Portugal como tendo sido «un texto historiográfico [...] en que la narración legendária se hallaba ya combinada con los datos genealógicos e analísticos referentes a los primeros reyes portugueses ${ }^{30}$ ». Pode ser que tivesse em mente sobretudo os reinados de Afonso Henriques e Sancho I, mas, e em todo o caso, é pena que a crítica portuguesa tenha deixado escapar tão importante pista de trabalho.

da Crónica Particular de S. Fernando. Veja-se, para além dos trabalhos referidos nas notas anteriores, Campa Gutiérrez (2003).

${ }^{28}$ Remeto, a este propósito, para Moreira (2008: 67-99), parecendo-me desnecessário repetir aqui tais argumentos. Mas faço notar a diferença existente quanto ao grau de certeza, digamos assim, do conteúdo do texto fonte da Versão Crítica e da Crónica Portuguesa de Espanba e Portugal: incluía seguramente o reinado de D. Afonso Henriques; muito provavelmente o de D. Sancho I e possivelmente os seguintes até o de D. Sancho II pelo menos.

${ }^{29}$ Como creio que se vai tornando evidente, não deve haver uma única página do meu estudo que não seja, pelas mais variadas razóes, devedora do De Alfonso X al Conde de Barcelos. Ainda assim, permito-me chamar a atenção para o facto de o terceiro estudo deste livro ostentar, como cabeçalho das suas páginas, a designação «La primera crónica portuguesa». O texto a que Catalán aplicava essa designação não é propriamente o mesmo a que eu me refiro; mas a lógica da designação é idêntica.

${ }^{30}$ Ed. Catalán e Andrés (1970: XLIV). 
Admitida a possibilidade de existência de uma pequena crónica dos reis de Portugal na segunda metade do século XIII grosso modo correspondente a dois terços daquilo que hoje se lê no manuscrito da $I V^{a}$ Crónica Breve, deveria logicamente seguir-se o problema da identificação dos seus promotores. A este respeito, penso que basta a circunstância de estarmos perante um texto que seria, antes de tudo o mais que se queira, uma história da dinastia real portuguesa, para termos de admitir como significativamente provável que essa mesma dinastia (ou meios a ela intimamente ligados, para retomarmos a expressão de Cintra) tenha sido a sua promotora, e de facto não vejo razóes para que assim não tenha sido. Pelo menos de uma coisa estou certo: se tivesse de agrupar esta Primeira Crónica Portuguesa em determinada família textual, essa seria, sem dúvida, a da cronística régia, e isto não só em virtude do objecto de que se ocupa, mas também graças à mundividência que nela se estrutura, a qual, basicamente centrada no problema das origens, legitimidade, transmissão, modelização e caracterização da realeza ${ }^{31}$, patenteia o mesmo tipo de preocupações que encontraremos em textos posteriores de segura ligação ou iniciativa régia. De tal modo isto é assim que se pode falar numa verdadeira tradição de crónicas régias portuguesas, a qual, partindo da Primeira Crónica Portuguesa e suas ampliaçôes (aspecto de que em seguida me ocuparei), e passando sucessivamente pela secção dedicada aos reis portugueses na Crónica de 1344, pela Crónica de 1419 e pelos cronistas manuelinos revela, a par de evidentes e compreensíveis diferenças, a manutenção, por vezes ipsis verbis, das mais variadas ideias, temas e narrativas. O processo é interessante: de crónica para crónica, verifica-se um substancial acréscimo de matéria; mas a espinha dorsal de cada uma delas assenta, por inteiro, na crónica anterior. O que, se, por um lado, terá contribuído para certa canibalização textual e consequente rarefacção de manus$\operatorname{critos}^{32}$, por outro denota uma curiosa linha de continuidade na forma como a monarquia portuguesa se foi representando ao longo dos últimos séculos da Idade Média.

Isto dito, é claro que as questôes suscitadas por esta Primeira Crónica Portuguesa não se esgotam neste leque de - e sublinho a palavra - hipóteses. Há mais e há talvez melhor. Limitar-me-ei, porém, e antes de tentar a súmula final acerca das origens da historiografia régia em Portugal, a alguns outros aspectos.

\footnotetext{
31 Detalhei estes aspectos em Moreira (2008: 81-92).

32 Pode, com efeito, supor-se que o facto de cada uma destas crónicas ter incorporado a maior parte do texto da sua antecessora acabou por tornar algo desnecessárias as cópias dos textos mais antigos.
} 


\section{A Primeira Crónica Portuguesa e o Liber Regum Interpolado}

Acabámos de ver que a Primeira Crónica Portuguesa está no início de uma tradição que viria a dar, com os cronistas dos séculos XV e XVI, os seus frutos mais acabados. Mas importa atentar um pouco em outros aspectos do seu percurso e constituição.

Em Afonso Henriques e a primeira crónica portuguesa levantei, a este respeito, dois cenários: i) que o uso do Liber Regum Interpolado se tenha verificado, neste contexto, apenas até ao reinado de Afonso VI, pois, de aí em diante, e por razóes cronológicas, seguir-se-ia a história dos reis de Portugal; ii) que a junção da Primeira Crónica Portuguesa com material oriundo do Liber Regum Interpolado poderia ter-se verificado já desde o início e, consequentemente, que se poderia considerar a Crónica Portuguesa de Espanha e Portugal como uma simples fase de redacção da Primeira Crónica Portuguesa, caracterizada por algumas actualizaçóes e pontuais interpolaçôes; no limite, e em nome da clareza expositiva, até a designação «Crónica Portuguesa de Espanha e Portugal» poderia ser banida.

Após isso, a descoberta e ponderação de um importante facto que até aí tinha passado completamente despercebido levou-me a reformular esta problemática. De forma paradoxal, o primeiro destes cenários, que eu supunha o mais sólido, veio a revelar-se-me totalmente falso; mas, e em contrapartida, o segundo parece-me hoje não só perfeitamente defensável como, até, o mais lógico.

Sucede que Acenheiro, e ao contrário do que supunha Catalán, não aproveitou a Crónica Portuguesa de Espanha e Portugal apenas para dar conta da descendência de Afonso VI e de alguns episódios do reinado de D. Afonso Henriques. Embora a segunda parte da sua obra (isto é, aquela que vai de D. Pedro I a D. João II) seja, basicamente, e como notou Catalán, cópia do Sumário de Crónicas do ms. 290 Alcobacense da BN³3 há nela uma importante adição da responsabilidade do próprio Acenheiro, a qual se baseia explicitamente em «crónicas velhas». Trata-se de um animado episódio da época de Urraca I de Castela e Leão, em que seu filho Afonso Raimundez (o futuro Imperador Afonso VII), coadjuvado por um nobre da família dos Castro, prende sua mãe e respectivo companheiro, Pedro de Lara (que aqui é esposo legítimo da rainha). Bastaria a forma como Acenheiro se refere, neste ponto, à sua fonte para que considerássemos que também este trecho proveio da Crónica

${ }^{33}$ Catalán (1962: 217-218). O facto de Acenheiro ter baseado, segundo ele próprio afirma, esta parte do seu trabalho num Sumário preexistente e de esse Sumário poder ser identificado com o do ms. 290 é algo que não se pode descartar em nenhuma análise da sua obra. Basta ver as conclusóes a que, a este respeito, chega Sena (1967), para verificarmos os perigos de tal «esquecimento». 
Portuguesa de Espanha e Portugal; mas o mais interessante é que esse episódio surge também na Versão Crítica da Estoria de España, embora o seu redactor, norteado pelos princípios que habitualmente o regiam, tenha dado preferência ao relato do Arcebispo de Toledo o que explica as diferenças existentes entre o seu texto e o da citaçáo de Acenheiro. E, segundo noutra ocasião tive oportunidade de defender, esta coincidência não poderá senão explicar-se pelo facto de o episódio em causa provir, em última instância, do Liber Regum Interpolado, tendo daí passado, directa ou indirectamente, tanto para a Crónica Portuguesa de Espanha e Portugal como para a Versáo Crítica da Estoria de España ${ }^{34}$.

Ora, isto vem complexificar ainda mais o panorama que comecei por descrever. Em primeiro lugar, tenho de abandonar a minha ideia de que, em Portugal, o conteúdo do Liber Regum Interpolado foi usado apenas, e por razóes essencialmente funcionais, até ao reinado de Afonso VI, pois, como vimos, foi-o seguramente também, e pelo menos, quanto ao reinado de D. Urraca. Mas, e por outro lado, creio que isto reforça o segundo cenário atrás elencado. Notemos, com efeito, a seguinte série de coincidências:

i) A Versão Crítica conheceu e usou a Primeira Crónica Portuguesa e o Liber Regum Interpolado;

ii) A Primeira Crónica Portuguesa e o Liber Regum Interpolado circularam juntos em Portugal, em data incerta mas seguramente anterior a meados do século XIV;

iii) A estrutura da Primeira Crónica Portuguesa, denotando embora uma maior incidência em processos de junção de matérias que se diriam tipicamente cronísticos, é essencialmente a mesma do Liber Regum: uma genealogia régia entremeada de narrativas;

iv) As narrativas lendárias sobre a época de D. Afonso Henriques e D. Urraca presentes na Primeira Crónica Portuguesa e no Liber Regum Interpolado apresentam evidentes e estreitas semelhanças a vários níveis: em ambas, um futuro rei, coadjuvado por um importante membro de uma família nobiliárquica, defronta e prende sua mãe e respectivo marido, obrigando este último a prometer nunca mais atentar contra a terra e a exilar-se; até textualmente se notam as semelhanças, por exemplo, no momento de humilhação do marido preso ${ }^{35}$.

\footnotetext{
${ }^{34}$ Moreira (2009).

35 "e des ahi premdeo seo padrasto, e tomou-lhe menagem de núca mais tornar a sa madre; e foi-se o Comde Dom Pedro de Lara ultra mar» no texto oriundo do Liber Regum Interpolado, segundo a citação de
} 
Estes factos concatenam-se de forma tão clara, que resisto a considerá-los meras coincidências. Em meu entender, a Primeira Crónica Portuguesa conheceu já o Liber Regum Interpolado, usando-o como guia para a estruturação geral do seu discurso, como fonte para a História ibérica a partir de Pelayo e, possivelmente, até como modelo de alguns episódios. Em consequência, e segundo o que há pouco dizia, a designação "Crónica Portuguesa de Espanha e Portugal» poderá, a bem da clareza expositiva, eliminar-se. O que se terá passado é, muito simplesmente, que à Primeira Crónica Portuguesa se terão acrescentado, ao longo do tempo, pequenas actualizações e interpolaçóes; mas o núcleo essencial, constituído por uma história ibérica oriunda de certa versão do Liber Regum e por uma história dos reis de Portugal, estaria lá desde o início.

\section{A Primeira Crónica Portuguesa: origem dos seus componentes}

Por outro lado, localizar nisso a que tenho chamado Primeira Crónica Portuguesa o início da tradição cronística nacional não significa necessariamente que não tenham existido, a par da tradição analística que sabemos antiga ${ }^{36}$, outras espécies textuais que da família real portuguesa se ocupassem e das quais a própria Primeira Crónica possa ter sido devedora. A este respeito, julgo do maior interesse começar por recuperar aqui palavras de José Mattoso que, descontado certo e compreensível laconismo, consubstanciam uma hipótese que me parece perfeitamente válida e que tenho pena não ter visto ser aprofundada. Dizia, com efeito, o ilustre historiador em artigo de finais dos anos 70 dedicado à tradição genealógica portuguesa: «não possuímos hoje qualquer escrito consagrado expressamente à família real. Mas deve ter existido pelo menos um, porque surgem vestígios dele no $D e$ Rebus Hispaniae do arcebispo D. Rodrigo de Toledo pouco depois de 1243, no cronicon latino de Alcobaça, cuja última notícia data de 1355, na $I V a$ Crónica breve [...] e na chamada

Acenheiro (1824: 129); «e prendeo seu padrasto e sua madre. E o conde cuidou aa sseer morto, e fez-lhe preito e menajem que nunca entrasse em Purtugal. E disi foi-se pera terra d'ultra mar», na Primeira Crónica Portuguesa, ed. Moreira, (2008: 128-129); não há, nesta passagem, diferenças substanciais entre a IVa Crónica Breve, a Versão Crítica e o Livro de Linhagens, o que garante que seria esta a lição da Primeira Crónica Portuguesa. Terá ainda o seu interesse notar que, e ao arrepio destas narrativas, nem Pedro de Lara nem Fernão de Trava foram nunca historicamente casados com D. Urraca e D. Teresa. Trata-se certamente de uma estratégia narrativa: e como entender que ela possa ter surgido por acaso em dois textos que viriam a circular juntos?

${ }^{36}$ E sobre a qual se pode agora ver Bautista (2009). 
Crónica Breve do Arquivo Nacional [...]. Devia tratar-se [...] de um texto anterior a meados do século XIII e sucessivamente ampliado na corte portuguesa» ${ }^{37}$.

Devo confessar que a leitura destas palavras do Professor Mattoso provocou em mim um simpático alvoroço, pois creio que há de facto razóes para suspeitarmos a existência de algum texto genealógico, ou quiçá um pouco mais que isso, consagrado desde longa data à dinastia dos reis de Portugal que seria, além do mais, usado pela Primeira Crónica Portuguesa. Aqui deixo as mais importantes, poupando-me, porém, a pormenores.

Analisando o que seguramente seria a história do reinado de D. Afonso Henriques de acordo com a mencionada Primeira Crónica Portuguesa, penso que se observa nela, sem dificuldades de maior, a existência de três blocos textuais que tanto pela diversidade formal como pela existência de elementos linguísticos de ligação entre eles, indicia que tenham sido, em parte pelo menos, previamente independentes uns dos outros ${ }^{38}$ : um bloco narrativo centrado nas lutas do nosso primeiro rei com diversas forças oponentes (corresponderá à célebre «Gesta de D. Afonso Henriques» de que propositadamente não falei), um bloco genealógico sobre a descendência do rei e um bloco essencialmente analístico em que se tocam alguns dos seus actos militares e piedosos em estilo por vezes curiosamente próximo do testamentário ${ }^{39}$.

Destes três blocos textuais, aquele que designei por «analístico» surge também, com muito pequenas diferenças, num texto originário do Mosteiro de Santa Cruz de Coimbra, a chamada Ia Crónica Breve ${ }^{40}$, apresentando, além disso, notórias semelhanças com anais produzidos nesse mosteiro. Isso significa, muito plausivelmente, que esse bloco tem, em última instância, uma origem crúzia (segundo D. Catalán ${ }^{41}$ e I. Fernández-Ordóñez ${ }^{42}$ já notaram) e que, portanto, o redactor da Primeira Crónica Portuguesa teve acesso a materiais deste mosteiro ${ }^{43}$.

O outro sinal de existência de remotas tradições genealógicas sobre a família real portuguesa encontramo-lo na grande semelhança entre algumas passagens da obra

${ }^{37}$ Mattoso (1981: 45).

${ }^{38}$ Moreira (2008: 67-70). A divisão do texto consagrado ao reinado de D. Afonso Henriques em três blocos (narrativo, genealógico e analístico) remonta a Catalán (1962: 252-274).

39 Designadamente na informação acerca das dádivas concedidas pelo rei à Ordem do Hospital, para que chama muito pertinentemente a atenção Mattoso (2009). Haverá que notar, em todo o caso, que esta passagem consta também da Ia Crónica Breve. Veja-se a nota seguinte.

40 Ed. Peixoto (2000: 93).

${ }^{41}$ Catalán (1962: 269).

42 Fernández-Ordóńez (1993: 243-244).

43 Este bloco foi também objecto de atenção de Dias (2003: 125-134), trabalho cuja consulta devo à amabilidade da autora. 
do Toledano e o texto da Primeira Crónica Portuguesa, designadamente em relaçáo a D. Afonso $\mathrm{II}^{44}$, as quais semelhanças foi demonstrado por Diego Catalán não poderem explicar-se por derivação do texto português em relação ao latino ${ }^{45}$, mas que também não me parecem simplesmente atribuíveis ao acaso. Uma fonte genealógica comum ao Toledano e à Primeira Crónica, por mais estranha que a ideia pareça à primeira vista, é uma hipótese que não deverá ser posta de lado.

Também a respeito do bloco narrativo dedicado às lutas de $\mathrm{D}$. Afonso I com uma série de oponentes, literariamente o mais interessante e mais estudado de todos (mas também, sem dúvida, o mais complexo), se poderão postular dívidas para com textos anteriores, seja ao nível do aproveitamento de hipotéticas narrativas preexistentes, seja no que toca à reconfiguração e reorientação de alguns episódios constantes de textos historiográficos portugueses ou castelhano-leoneses. Pouco tenho, de momento, a acrescentar ao que recentemente disseram J. C. Miranda ${ }^{46}$ e J. Mattoso ${ }^{47}$, mas parece-me, ainda assim, oportuno notar que a tese da origem épica ${ }^{48}$ deste bloco parece estar a ser abandonada pela crítica; que as lutas de D. Afonso Henriques com a mãe e o padrasto deverão ser equacionadas também à luz do Liber Regum Interpolado, conforme acima indiquei; e que, independentemente da existência de hipotéticas narrativas anteriores que possam ter sido usadas pelo redactor da Primeira Crónica Portuguesa na feitura da estória de Afonso Henriques, considero que o resultado final do seu trabalho, longe de ser uma espécie de manta de retalhos, comporta assinaláveis níveis de coesão interna ${ }^{49}$.

Tudo isto significa que o redactor da Primeira Crónica Portuguesa não terá partido propriamente do nada, mas terá baseado o seu trabalho num processo de reunião, junção, harmonização, continuação e reorientação de textos preexistentes, processo, afinal, típico da historiografia da época.

${ }^{44}$ Repare-se que não estamos a falar apenas de coincidências na lista dos filhos deste rei, o que seria assaz irrelevante, mas sim de coincidências quanto à apreciação global do reinado e quanto ao facto de se atribuir a D. Afonso a conquista de Alcácer do Sal e outros castelos, dado anti-histórico. Veja-se um confronto entre o texto português e o latino em Catalán (1962: 280).

45 Catalán (1962: 280-281).

${ }^{46}$ Miranda (2009). A respeito das relaçōes existentes entre a Primeira Crónica Portuguesa e o Cronicon Lusitano (mais um texto oriundo de Santa Cruz de Coimbra), questão focada neste artigo, veja-se um outro aspecto em Catalán (1962: 249-250).

${ }^{47}$ Mattoso (2009).

${ }_{48}$ Tese cujo primeiro proponente foi Theodore Babbitt, segundo recorda Cintra (2009: CCCLXVI e $\mathrm{n}$. 135). O seu maior defensor viria a ser, porém, António José Saraiva: Saraiva (1991). Catalán deixou-nos uma cautelosa apreciação do problema em Catalán (2000: 53-58).

49 Segundo defendo em Moreira (2008: 25-50), retomando e ampliando observaçôes já feitas por Catalán (1962: 266-274); Neves (2001) e Barradas e Nabais (1996). 


\section{A Primeira Crónica Portuguesa: trajectória}

Apesar da brevidade e relativo esquematismo que, tanto quanto nos é dado ver, genericamente a caracterizaria, a verdade é que a Primeira Crónica Portuguesa teve uma notória difusão e jogou um importante papel na afirmação da historiografia régia em Portugal. Já vimos que ela foi usada pela Versão Crítica da Estoria de España ${ }^{50}$, pelo Livro de Linhagens do Conde D. Pedro e pela Crónica de 1344, passando o seu texto, a partir do momento em que foi incorporado por esta última obra, a constituir a espinha dorsal de várias outras crónicas posteriores. É esse, sem dúvida, o seu maior legado, e particularmente no que se refere a D. Afonso Henriques, cuja imagem mítica é, ainda hoje, e mau grado múltiplas reformulaçôes posteriores, marcada pelo que o seu anónimo redactor decidiu criar e/ou recriar ${ }^{51}$. Mas, para além de Afonso X, de D. Pedro e de Santa Cruz (onde, afinal, se copiou o texto mais próximo do original da Primeira Crónica) há ainda um outro centro produtor que a conheceu e modelou, e com o qual terminarei este conjunto de reflexóes: refiro-me ao mosteiro de Alcobaça. Com efeito, o manuscrito da IVa Crónica Breve contém uma narrativa fundacional desse mosteiro, cujas personagens centrais são D. Afonso Henriques e seu suposto irmão D. Pedro Afonso, que não figura nem na Versáo Crítica, nem no Livro de Linhagens, nem na Crónica de $1344^{52}$ e pode, por isso, considerar-se uma interpolação ao texto original da Primeira Crónica Portuguesa. Ora, parece evidente a origem alcobacense desta narrativa, facto que é, aliás, corroborado pela sua presença, em contexto idêntico ao da IVa Crónica Breve, num manuscrito oriundo desse mosteiro ${ }^{53}$.

${ }^{50}$ As conhecidas relaçôes familiares existentes entre Afonso X e Afonso III (sogro e genro) poderẫo explicar que uma cópia da Primeira Crónica tenha chegado às mãos do Rei Sábio - e quem sabe também explicarão, em sentido contrário, que o Liber Regum Interpolado tenha sido conhecido em Portugal. Deve, porém, ter-se em conta que a Estoria de España recorreu também a textos crúzios (Cronicon Lusitano), podendo, por conseguinte, $S$. Cruz ter tido alguma espécie de papel neste intercâmbio textual.

${ }^{51}$ Haja em vista, sobretudo, a prisão de D. Teresa pelo filho, ou, porventura, até a associação de Ourique ao início da realeza de D. Afonso Henriques, aspecto que, embora possa ter algo de historicamente verdadeiro, terá dado entrada na produção historiográfica a partir justamente da Primeira Crónica (não obstante dever ser meditada uma observação de Francisco Bautista acerca de uma possível alusão a este facto contida nuns antigos anais de S. Cruz: Bautista (2009: 175-176).

${ }^{52}$ Mau grado certa afirmação elíptica da Crónica de 1344 que poderá ser entendida como alusão ao mesmo episódio; mas, para além do carácter dubitativo dessa alusão, deve notar-se que a $I I I^{a}$ Crónica Breve, que é cópia do reinado de D. Afonso Henriques segundo a Crónica de 1344, não a contempla.

53 Veja-se Cintra (2009: CCCLXXIII). Trata-se do manuscrito que contém o texto normalmente conhecido pela designação De Expugnatione Scalabis, mas ao qual letra posterior juntou a narrativa da fundação de Alcobaça bem como as informaçōes que, na IVa Crónica Breve, a rodeiam e remontam certamente à Primeira Crónica Portuguesa. Este fragmento da Primeira Crónica merece, sem dúvida, um pouco mais de atençáo do que aquela que lhe tem sido concedida. Faço notar que, segundo propôs Tarouca (1951), é possível que este fragmento tenha sido manejado pelo redactor da Crónica de 1419, o que diz bem da sua antiguidade. 
Quer isto dizer que Alcobaça, tal como Santa Cruz, podem não ter sido os promotores da Primeira Crónica Portuguesa; mas conheceram-na e vieram a ficar indissoluvelmente ligados ao seu trajecto ${ }^{54}$.

\section{As origens da historiografia régia portuguesa: súmula}

É agora altura de deixar resumido o que julgo ter sido o processo de elaboração de uma historiografia régia portuguesa. Assim, a par da vetusta tradição analística continuadamente elaborada em mosteiros, terá existido desde longa data uma espécie de textos de cariz genealógico especificamente dedicados à família real. Ou nos primeiros anos do reinado de D. Dinis ou, e talvez mais provavelmente, ainda no tempo de D. Afonso III, e em meios afectos à corte régia, essa produção textual terá conhecido duas importantes novidades: usou-se pela primeira vez a língua vulgar e, dando-se mostras de um razoável amadurecimento técnico, procedeu-se à reunião, junção, harmonização e modelização de materiais preexistentes, originando-se assim a Primeira Crónica Portuguesa, texto independente da pujante tradição historiográfica de que já então se ia encarregando o scriptorium de Afonso $\mathrm{X}^{55}$. Este primeiro impulso de criação de uma historiografia régia portuguesa, a que decerto não será alheia uma visão progressivamente encarecedora da instituição monárquica, terá tomado como guia uma versão do Liber Regum certamente originária do reino de Castela e Leão e caracterizada por uma assinalável presença de trechos lendários (Moura Zaida, D. Urraca e Afonso VII), que terá influído directamente no estilo e na configuração da estória de Afonso Henriques, trecho literariamente mais notável da Primeira Crónica Portuguesa. Entretanto, a cronística afonsina, que já se tinha aproveitado deste labor pioneiro, chega a Portugal e, nas mãos de Pedro Afonso de Barcelos, verdadeiro ponto de encontro de tradiçóes régias e nobiliárquicas tanto portuguesas como castelhanas, funde-se

\footnotetext{
${ }_{54}$ À imagem do que terá sucedido com outros textos, designadamente o referido De Expugnatione Scalabis, também neste caso se verifica um intercâmbio textual entre Alcobaça e Santa Cruz: aquele mosteiro terá interpolado na Primeira Crónica Portuguesa a narrativa da sua fundação, vindo o texto assim constituído a ser conhecido e copiado em Santa Cruz. Acrescento, para terminar este apartado, que também a chamada Crónica Breve do Arquivo Nacional, texto redigido na corte de D. João I em 1429, conheceu uma cópia (e uma boa cópia) da Primeira Crónica Portuguesa, baseando nela grande parte das informaçóes sobre D. Sancho I, bem como a notícia do casamento de D. Afonso Henriques. Veja-se Cintra (2009: CCCLII-CCCLIII).

55 Note-se que a cronologia, o procedimento e, porventura, parte das motivações de ambos estes projectos historiográficos terão sido muito semelhantes; simplesmente, e como é óbvio, a tradição historiográfica, já então fortíssima, que vinha sendo patrocinada pela coroa castelhano-leonesa, bem assim como os meios humanos e materiais de que dispunha Afonso X, explicam a enorme diferença quanto aos resultados finais.
} 
com a produção local dando origem à prosa historiográfica mais extensa que até então conhecêramos: o Livro de Linhagens e a Crónica de 1344, esta última, elo de ligação com os textos patrocinados pela dinastia de Avis. Ao mesmo tempo, os mosteiros de Santa Cruz e Alcobaça contribuíram também para a feitura (no primeiro caso) e para a preservação e difusão (em ambos os casos) da Primeira Crónica, deixando, assim, o seu nome indelevelmente ligado ao das origens da cronística régia em Portugal.

É claro que o que aqui fica não é senão a tentativa de, a traço grosso e sem esquecer anteriores construtores, erigir um edifício minimamente consistente. A robustez das suas partes é, porém, variável: certas peças encaixam melhor que outras, a fachada aguentar-se-á talvez mais que as traseiras, algumas brechas ficam por preencher e o autor será o primeiro a recusar permanecer muito tempo debaixo desta ou daquela abóbada. Outros arquitectos, outros engenheiros e outros operários são sem dúvida necessários. Todavia, e permito-me citar o Professor José Mattoso ${ }^{56}$, é preciso cuidado, pois «o seu equilíbrio não é muito sólido! Se se mexer muito, pode cair tudo no chão! Para alterar o traçado, é preciso ser bom pedreiro ou ser bom arquitecto. Convém tomar precauções para não baralhar tudo de tal maneira que seja impossível ter a mínima ideia da traça primitiva».

\footnotetext{
${ }^{56}$ Mattoso (2006: 15).
} 


\section{Bibliografia:}

Acenheiro, Cristóvão Rodrigues (1824). Chronicas dos Senhores Reis de Portugal. Tomo V da "Collecção de

Inéditos da História Portugueza». Lisboa: Real Academia das Sciencias.

Babbitt, Theodore (1934). «Observations on the Crónica de Once Reyes». Hispanic Review, 2(3), pp. $202-216$.

Barradas, Aurélio e Fernando Nabais (1996). "A gesta de D. Afonso Henriques: épica e ética». In Actas do $2^{\circ}$ Congresso histórico de Guimarães, vol. 3, pp. 57-80. Guimarães: Câmara Municipal e Universidade do Minho.

Basto, Artur de Magalhães (1960). Estudos. Cronistas e Crónicas Antigas. Fernão Lopes e a "Crónica de 1419". Coimbra: Imprensa da Universidade de Coimbra.

Bautista, Francisco (2009). «Breve historiografía: Listas regias y Anales en la Península Ibérica (Siglos VII-XII)». Talia Dixit, 4, pp. 113-190. URL: http://www.unex.es/arengas/taliadixit4.htm. [Consultado a 17/11/2009]. Campa Gutiérrez, Mariano de la (2003). «Crónica de Veinte Reyes». Revista de Literatura Medieval, 15(1), pp. 141-153.

- (2009). Estoria de España de Alfonso X. Estudio y Edición de la Versión Crítica desde Fruela II hasta la muerte de Fernando II. Analecta Malacitana, Anexo LXXV. Málaga: Universidad de Málaga.

Catalán, Diego (1962). De Alfonso X al Conde de Barcelos. Cuatro estudios sobre el nacimiento de la historiografía romance en Castilla y Portugal. Madrid: Gredos.

- (1976). Gran Crónica de Alfonso XI. Madrid: Gredos.

- (1992). La Estoria de España de Alfonso X. Creación y Evolución. Madrid: Fundación Ramón Menéndez Pidal.

- (2000). La Épica Española. Nueva Documentación y Nueva Evaluación. Madrid: Fundación Ramón Menéndez Pidal.

Catalán, Diego e Maria Soledad de Andrés (1970). Edición Critica del Texto Español de la Crónica de 1344 que Ordenó el Conde de Barcelos don Pedro Alfonso. Madrid: Gredos/Fundación Ramón Menéndez Pidal.

Cintra, Luis Filipe Lindley (2009). Crónica Geral de Espanha de 1344, vol. I (Introdução). Lisboa: Imprensa Nacional Casa da Moeda (reimp. da ediçấo de 1951).

Dias, Isabel (2003). Culto e Memória textual de S. Vicente em Portugal (da Idade Média ao século XVI) (Dissertaçáo de Doutoramento apresentada à Universidade do Algarve, policopiada).

Faria, Isabel Hub (1999). Lindley Cintra. Homenagem ao homem, ao mestre e ao cidadão. Lisboa: Cosmos.

Fernández-Ordóńez, Inés (1993). La Versión Crítica de la Estoria de España. Estudio y Edición desde Pelayo hasta Ordoño II. Madrid: Fundación Ramón Menéndez Pidal/Universidad Autónoma de Madrid.

Lanciani, Giulia e Giuseppe Tavani (2000). Dicionário da Literatura Medieval Galega e Portuguesa (2a ed.). Lisboa: Caminho.

Maurício, Carlos Coelho (1989). «Entre silêncio e ouro - sondando o milagre de Ourique na cultura portuguesa». Ler História, 16, pp. 3-28. 
Mattoso, José (1981). A Nobreza medieval portuguesa. Lisboa: Estampa.

— (2006). D. Afonso Henriques. Lisboa: Círculo de Leitores.

— (2009). «A primeira Crónica Portuguesa». Medievalista online, 6. URL: http://www2.fcsh.unl.pt/iem/medievalista/MEDIEVALISTA6/medievalista-mattoso.htm. [Consultado a 15/11/2009].

Miranda, José Carlos (2009). «Na génese da Primeira Crónica Portuguesa». Medievalista online, 6. URL: http://www2.fcsh.unl.pt/iem/medievalista/MEDIEVALISTA6/medievalista-miranda.htm. [Consultado a $15 / 11 / 2009]$

Moreira, Filipe Alves (2008). Afonso Henriques e a primeira crónica portuguesa. Porto: Estratégias Criativas.

— (2009). «Um novo fragmento da Crónica Portuguesa de Espanha e Portugal de 1341-1342 e suas relaçóes com a historiografia afonsina». Guarecer on-line (fundo de publicaçóes do Seminário Medieval de Literatura, Pensamento e Sociedade). URL: http://www.seminariomedieval.com/guarecer/fam2009.pdf. [Consultado a $9 / 10 / 2009]$.

Neves, Leonor Curado (2001). «Uma Épica Medieval Portuguesa?». In História da Literatura Portuguesa, vol. I: Das origens ao Cancioneiro Geral, pp. 163-187. Lisboa: Alfa.

Peixoto, Fernando Venâncio (2000). Crónicas Breves e Memórias Avulsas de S. Cruz de Coimbra. Lisboa: Edição do autor.

Pimenta, Alfredo (1948). Fontes Medievais da História de Portugal. Lisboa: Sá da Costa Editora.

Saraiva, António José (1969). «Sur le texte de la tradition épique d’Afonso Henriques: Analyse stylistique comparée des versions de la Cronica de Veinte Reys et de la Quarta Crónica de Santa Cruz de Coimbra», Bulletin des Études Portugaises. Nouvelle Série, 30, pp. 11-37.

— (1991). A Épica Medieval Portuguesa (2a ed.). Biblioteca Breve. Lisboa: ICALP.

Sena, Jorge de (1967). Estudos de História e de Cultura, vol. I. Lisboa: Revista Ocidente.

Tarouca, Carlos da Silva (1951). «Terão aparecido as crónicas perdidas de Fernão Lopes?». Lisboa: Separata da Revista Brotéria.

Veiga, Artur Botelho da Costa (1939). Estudos de História Militar Portuguesa. Lisboa: Edição do autor.

Villanueva, J. Pérez (1991). Ramón Menéndez Pidal. Su vida y su tiempo. Madrid: Espasa Calpe. 